\title{
Will Quebec influence Ontario's IVF plans?
}

$\mathrm{M}$ ore than a year has passed since the Ontario government pledged financial help to Ontarians seeking fertility treatments. At the time of the announcement, neighbouring Quebec was offering the most extensive publicly funded fertility care in the country. But as Quebec now moves to drastically downscale its program, is Ontario having second thoughts?

A statement from the office of the minister, Dr. Eric Hoskins, says they are "on track" to launch the program later in 2015.

"It really is taking as long as it's taking for good reason," says Amir Attaran, a law professor at the University of Ottawa and one of three patient representatives on an advisory panel set up in December 2014; the 10 other members are physicians. Panel members are bound by a confidentiality agreement.

It is widely acknowledged that Quebec was too generous; some called it an "open bar." Multiple rounds of in vitro fertilization (IVF) toward multiple children were covered under the province's health care plan, and there were no restrictions on maternal age beyond those imposed by individual clinics. Nor were there restrictions on cause of infertility, including tubal ligation or vasectomy.

"The Quebec government maybe didn't think it through as well as they should have," says Dr. Heather Shapiro, vice president of the Canadian Fertility and Andrology Society (CFAS), which represents fertility doctors.

According to CFAS numbers, the cost to the Quebec government, per baby, went up dramatically with a mother's age. Under age 35, the cost per live birth was $\$ 17919$. At age 40 , it was $\$ 43153$, and at age 43, \$103 994 .

"If it's a publicly funded system," says Dr. Neal Mahutte, CFAS president and medical director of the Montreal Fertility Center, "it makes sense to have a cut-off."

The April 2014 announcement by the Ontario government suggested it would

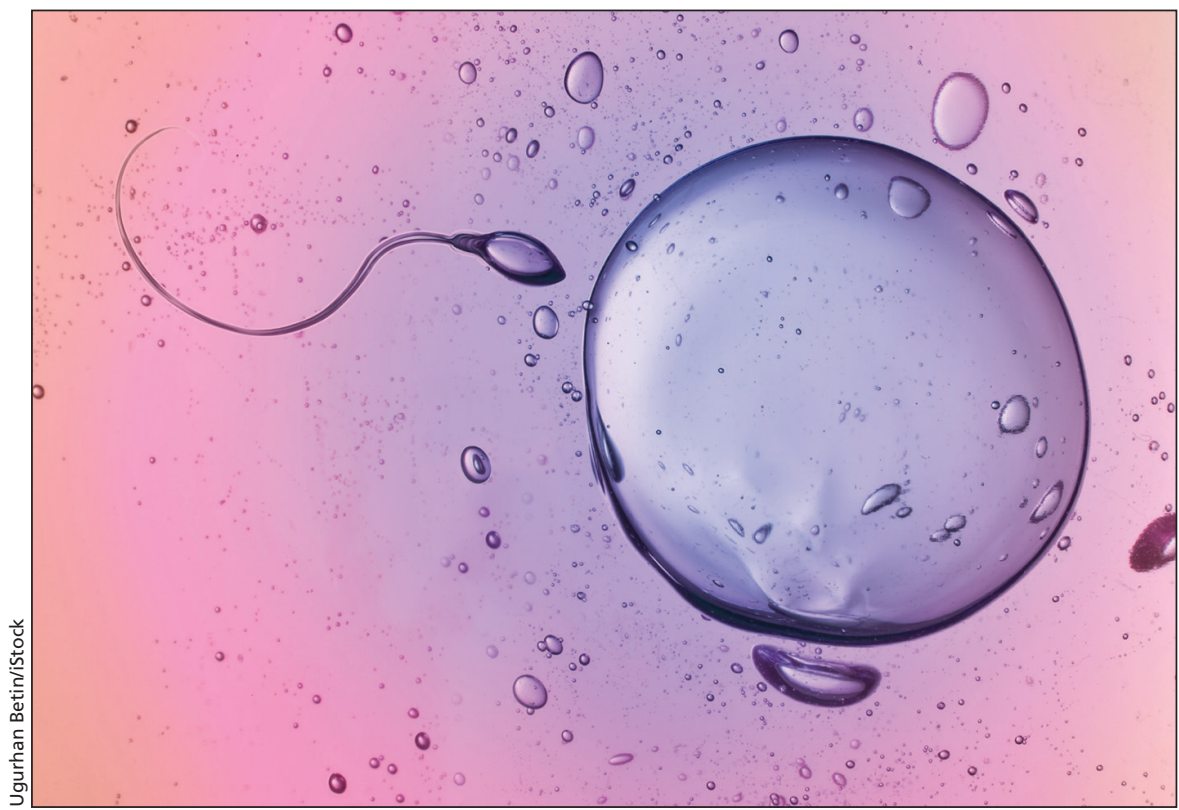

Quebec couldn't afford its in vitro fertilization program and decided to drastically downscale it earlier in 2015.

likely only contribute toward one round of IVF and that the cost of drugs which can account for about half the cost of the procedure - would not be included. It also said it would fund the transfer of only one embryo at a time, in an effort to reduce multiple births, which are associated with negative health outcomes. Quebec also adopted this policy, and within the first year after implementation, the IVF multiple birth rate dropped from $29 \%$ to just $7 \%$, where it remains. The rate in the rest of Canada has only declined to $21 \%$.

Eligibility in Ontario remains uncertain. Unlike in Quebec, there may be an age cut-off.

"Success rate diminishes substantially somewhere between age 42 and 44," says Dr. Marjorie Dixon, medical director of First Steps Fertility in Toronto and an advocate for public funding with the group, OHIP for IVF Coalition. There may be other restrictions as well, including a potential mother's extremely high or low body mass index, which affects success rates.
What is also unclear is how Ontario will choose to provide help. Medical treatments funded directly through OHIP, the provincial insurer, are typically deemed "medical necessities" combatting "diseases", says Carolyn McLeod, a philosopher at the University of Western Ontario, in London, who specializes in health care ethics. But that would make it difficult to assist gay men or lesbians, she says. "The medical necessity argument is a tough one to make."

Instead, Ontario may choose to provide a tax credit, which, instead of providing an insured medical service, would provide some after-the-fact reimbursement. Manitoba takes this approach, reimbursing $40 \%$ of the cost of fertility treatments up to a total reimbursement of $\$ 8000$. However, if Ontario goes this route, McLeod argues, the province would be morally bound to provide equal support to parents who choose to adopt. - Alison Motluk, Toronto, Ont.

CMAJ 2015. DOI:10.1503/cmaj.109-5057 